\title{
Voltammetry Method Evaluation
}

\section{Fuel Cycle Research \& Development}

\section{Prepared for}

U.S. Department of Energy Material Protection, Accounting, and Control Technologies Campaign

N. Hoyt, C. Pereira, J. Willit, M. Williamson Argonne National Laboratory July 29, 2016 
DISCLAIMER

This information was prepared as an account of work sponsored by an agency of the U.S. Government. Neither the U.S. Government nor any agency thereof, nor any of their employees, makes any warranty, expressed or implied, or assumes any legal liability or responsibility for the accuracy, completeness, or usefulness, of any information, apparatus, product, or process disclosed, or represents that its use would not infringe privately owned rights. References herein to any specific commercial product, process, or service by trade name, trade mark, manufacturer, or otherwise, does not necessarily constitute or imply its endorsement, recommendation, or favoring by the U.S. Government or any agency thereof. The views and opinions of authors expressed herein do not necessarily state or reflect those of the U.S. Government or any agency thereof. 


\section{Completion of Voltammetry Method Evaluation}

\section{Overview}

The purpose of the ANL MPACT Voltammetry project is to evaluate the suitability of previously developed cyclic voltammetry techniques to provide electroanalytical measurements of actinide concentrations in realistic used fuel processing scenarios. The molten salts in these scenarios are very challenging as they include high concentrations of multiple electrochemically active species, thereby creating a variety of complications. Some of the problems that arise therein include issues related to uncompensated resistance, cylindrical diffusion, and alloying of the electrodeposited metals. Improvements to the existing voltammetry technique to account for these issues have been implemented, resulting in good measurements of actinide concentrations across a wide range of adverse conditions.

\section{Introduction}

Accurate measurement of actinide concentrations is critical for the protection, accountancy, and control of nuclear materials within molten salts. Electroanalytical techniques using cyclic voltammograms (CVs) are a promising approach that has been developed to provide these measurements. Earlier voltammetry studies conducted at Argonne National Laboratory showed that CVs were able to provide very accurate results at low concentrations for single and multicomponent salts [1]; however, at high concentrations the electroanalytical measurements were found to deviate considerably from inductively coupled plasma / atomic emission spectroscopy (ICP/AES) results [2].

This project is therefore intended to assess the applicability of an improved voltammetry methodology to realistic fuel processing scenarios - situations that necessarily involve high-concentration multicomponent salts. The four scenarios of interest include the following conditions: (i) high $\mathrm{U}$, low $\mathrm{Pu}$, (ii) high $\mathrm{Pu}$, low $\mathrm{U}$ (iii) $\mathrm{U}, \mathrm{Pu}$, and $\mathrm{Np}$ at prototypical steady-state (iv) high $\mathrm{U}$, low $\mathrm{Pu}$, high $\mathrm{Gd}$.

\section{Experimental Approach}

The same general experimental technique as used is previous studies is used in this project [1]. By linearly sweeping the potential of an electrode immersed in the molten salt, the concentration of an electrochemically active constituent can be determined through analysis of its corresponding peak current. The area of the electrode must be known in order to convert the peak current into a corresponding concentration value. As the depth of the working electrode in the salt is difficult to determine with high precision, the standard area-addition method is used where the working electrode is translated up and down fixed distances. Doing so allows for the current per unit depth to be calculated, thereby permitting use of analytical formulas to determine the desired concentration. 
Figure 1 shows a schematic of the experimental setup. The working and quasireference electrodes are $1 \mathrm{~mm}$ diameter tungsten rods, and the counter electrode is a $2 \mathrm{~mm}$ diameter tungsten rod. The molten salt consisted of $\mathrm{LiCl}-\mathrm{KCl}$ eutectic $(44.2 \mathrm{wt} \% \mathrm{LiCl})$ along with varying weight percentages of $\mathrm{UCl}_{3}, \mathrm{PuCl}_{3}$, and $\mathrm{GdCl}_{3}$. The plutonium content was sourced from a $6 \mathrm{wt} \% \mathrm{LiCl}-\mathrm{KCl}-\mathrm{PuCl}_{3}$ salt that had been created from the chlorination of $\mathrm{PuO}_{2}$. Small amounts of $\mathrm{ZrCl}_{4}$ are also present in some of the final salts due to its use in the chlorination process. The crucible was composed of Inconel. Electrochemical testing was performed using a Gamry Interface 5000 potentiostat. CVs were typically performed with $50-100 \mathrm{mV} / \mathrm{s}$ scan rates to ensure reversibility of the kinetics. An electrochemical cleaning process was used in between $\mathrm{CVs}$ to ensure repeatability of the results. The cleaning consisted of an anodic potentiostatic hold $(+0.05 \mathrm{~V}$ versus the quasireference electrode) followed by a long duration ( $3 \mathrm{~min}$.) open circuit hold to allow the potential between the working electrode and quasireference electrode to return to a value less than $500 \mu \mathrm{V}$. At present, the concentrations of active species in the salts is known only through process knowledge; however, analytical tests (ICP/AES) to confirm these values are to be performed shortly.

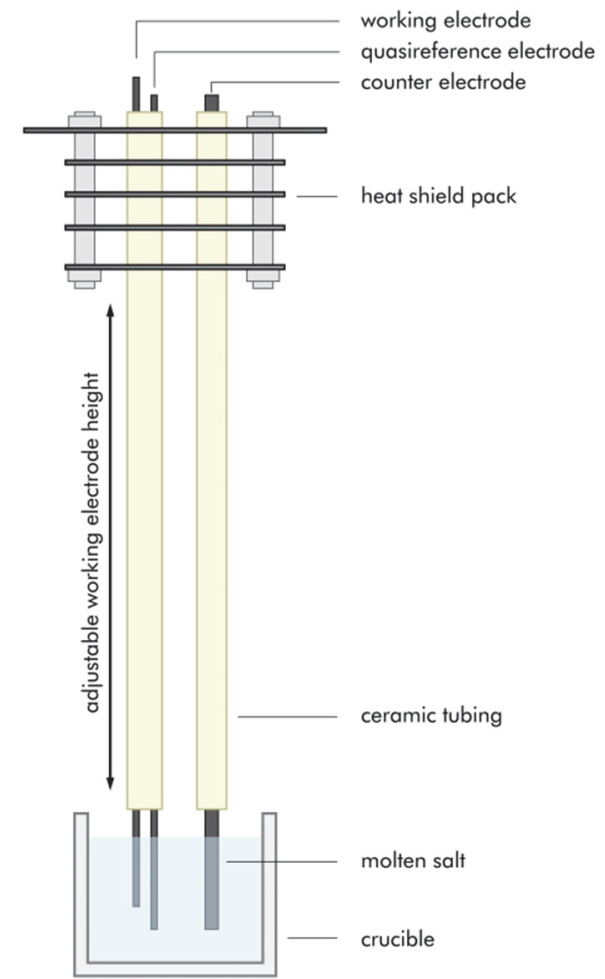

Figure 1. Experimental setup (not to scale)

\section{Analytical Approach}

While the experimental approach is largely the same as that used in the past, improvements in modeling needed to be incorporated in order to account for complications that arise in realistic fuel processing scenarios. These issues occur as molten salts in these situations necessarily contain large concentrations of multiple actinide species. Some of the complications that have been addressed are discussed in detail below.

\subsection{Uncompensated Resistance}

The first complication that arises with a realistic molten salt composition is related to the solution resistance. Even in a highly conductive solution such as a molten salt, the large currents that are induced by high concentrations of reactants can lead to non-negligible voltage shifts - so-called $i R$ effects - that serve to distort the voltammetric response. Simulation results showing the effects of $i R$ are included in Figure 2.

The $i R$ serves to alter the current response of the voltammogram by changing the effective potential at the working electrode. Specifically, $E_{\text {elec }}=E_{\text {applied }}-i R_{u}$, where $E_{\text {elec }}$ is the actual electrode potential, $E_{\text {applied }}$ is the applied potential, $i$ is the current, and $R_{u}$ is the uncompensated resistance of the system. The presence of uncompensated resistance therefore nonlinearly alters the effective scan rate of the voltage sweep, thereby leading to depressed peak currents and dilation of the peak width [3]. Use of peak currents affected by $i R$ therefore inherently lead to underestimates of the reactant concentration unless steps are made to take the non-ideality into account. 
Effects from the uncompensated resistance were not considered in the previously developed voltammetric methodology, but must be included for realistic molten salts. Positive-feedback $i R$ compensation is provided in most modern potentiostats to address these effects experimentally, but instability in the feedback mechanisms tend to introduce artifacts into the data and can only permit compensation of at most $\sim 90 \%$ of $R_{u}$ (which is determined prior to the $\mathrm{CV}$ via electrochemical impedance spectroscopy) [4]. As extremely high accuracy is sought for the molten salt measurements, the use of digital simulations that include $i R$ effects (to be matched to uncompensated experimental data) has been chosen in lieu of $i R$ compensation.

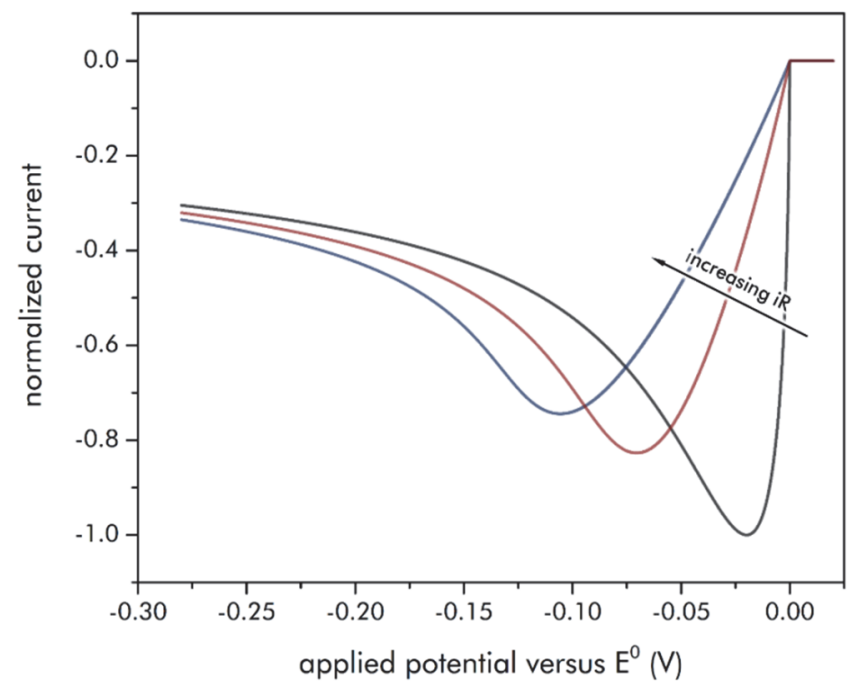

Figure 2. Cyclic voltammetry simulation results (reduction sweep) showing the effect of uncompensated resistance on a reversible soluble/insoluble reaction

\subsection{Cylindrical Diffusion}

Cylindrical diffusion effects are another complication that arise with realistic salts owing to the concomitant $i R$ shifts. As $i R$ serves to dilate the amount of time required to reach the peak potential, the diffusion layer is able to grow large enough that cylindrical spatial effects become non-negligible. The effect of cylindrical diffusion on the peak current is generally relatively small (typically the peak current is increased by a few percent and the peak potential is shifted negative by a few millivolts), but ignoring the effect nonetheless results in errors to the predicted concentrations; hence, digital simulations that include cylindrical diffusion effects have been adopted for the analysis of the voltammetric data.

\subsection{Underpotential Co-deposition}

The third complication that results from realistic molten salt compositions is underpotential co-deposition. The previous electroanalytical approach had used analytical formulas (such as the Berzins-Delahay equation [5]) that assumed unit activity of the deposited metal. In general, the unit activity assumption works very well for the linear sweep of the $\mathrm{U}^{3+} / \mathrm{U}^{0}$ reaction. However, in the presence of a co-deposited metal (e.g., for the linear sweep of the $\mathrm{Pu}^{3+} / \mathrm{Pu}^{0}$ reaction where uranium is still actively being deposited), the activity of the deposit can change considerably depending on the composition of the alloy that exists at the surface of the working electrode. Figure 3 includes simulation results demonstrating the effect of the resulting underpotential co-deposition (UPCD) on the current response of $\mathrm{Pu}$ when background $\mathrm{U}$ deposition is occurring simultaneously. The figure includes curves for the unit-activity assumption, and for two different regular and sub-regular activity models for the U-Pu alloy [6-8].

In general, the activity of the reactant in the deposited metal is less than unity, which, in accordance with the Nernst equation, shifts the plating potential of the co-deposited reactant to more positive potentials [9]. This shift alters the current response, ultimately reducing the peak current that is achieved. Thus, in order to not underestimate the reactant concentration, any analytical predictions resulting from analysis of the peak current must take into account underpotential co-deposition effects. 


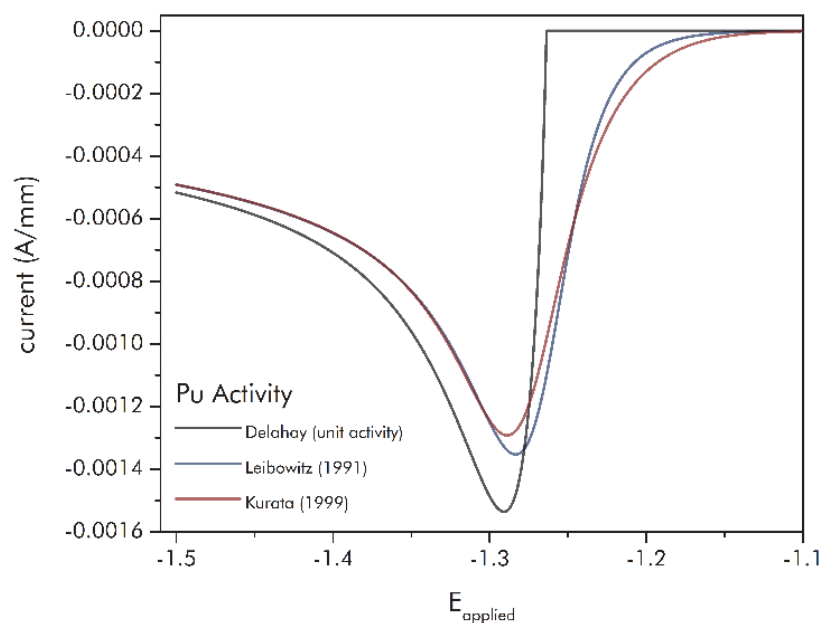

Figure 3. Effect of UPCD on simulated voltammograms (reduction sweep) for reversible soluble/insoluble reaction
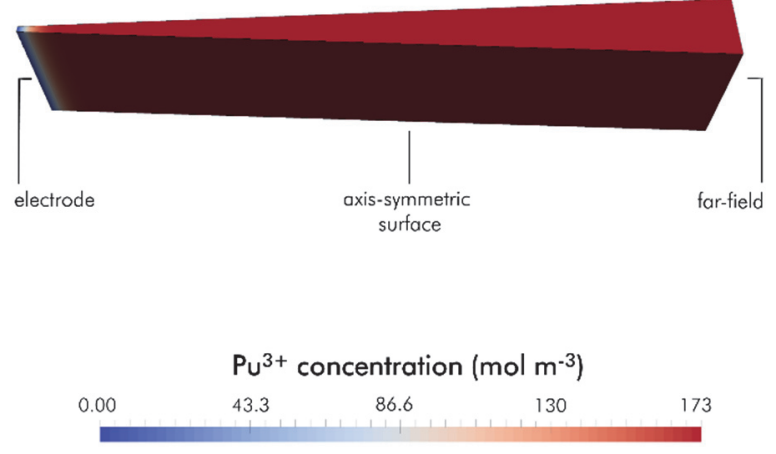

Figure 4. Typical numerical solution showing diffusion layer growth from electrode surface during reduction sweep

\section{Numerical Modeling Approach}

The determination of actinide concentrations from $\mathrm{CVs}$ thus requires fits of digital simulations to the experimental data in order to fully take into account all of the combined effects of $i R$, cylindricity, and UPCD. These simulations were conducted using a custom solver developed within OpenFOAM, an opensource numerical modeling toolkit. Figure 4 shows the growth of the diffusion layer during a typical simulation. The $i R$ and UPCD effects are taken into account using nonlinear boundary conditions at the electrode. The effects of cylindrical diffusion are inherently taken into account through use of the axisymmetric wedge geometry.

\section{Results}

\subsection{Method Application to High Concentration Single-Component Salts}

In order to assess the new analytical approach, tests were first run on single component salts containing 0$8 \mathrm{wt} \%$ uranium. These tests were not specifically included among the four realistic fuel processing scenarios in Work Item 1 of this project, but they serve as a test of the efficacy of the $i R$ and cylindrical diffusion treatment. Similar cases (with $U$ quantities varying from 0-9 wt\%) had been tried in the past, but it was found that at high weight percentages the predicted concentrations were lower than expected [2].

A typical voltammogram for the $6.5 \mathrm{wt} \% \mathrm{U}$ case is shown in Figure 5 . The $\mathrm{CV}$ shows clear signs of uncompensated resistance as the peak rise width, $E_{p}-E_{i}$ (see figure), has dilated to a value of $80 \mathrm{mV}$, as compared to the ideal, resistance-free value of $18.9 \mathrm{mV}$ (valid for a three electron process at $500{ }^{\circ} \mathrm{C}$ ). The extra time associated with this dilation permits the diffusion layer to become increasingly thick, thereby ultimately reducing the peak current.

Thus, when using the standard Berzins-Delahay equation to determine the concentrations, the predicted values are substantially lower than the actual, known concentrations. This can be seen in Figure 6, where the predicted concentrations without the $i R$ /cylindricity treatment are well below the parity line. However, if digital simulations including $i R$ and cylindrical diffusion effects are instead used, the predicted concentrations are very close to the actual, known concentrations. This result can be seen in Figure 6 
where the data with $i R /$ cylindricity are very close to the parity line. While it had been previously speculated that a reduction in the diffusion coefficient of the $\mathrm{U}^{3+}$ ion at high concentrations explained the depressed analytical results using cyclic voltammetry, it appears that $i R$ effects are the cause for much of the original discrepancy.

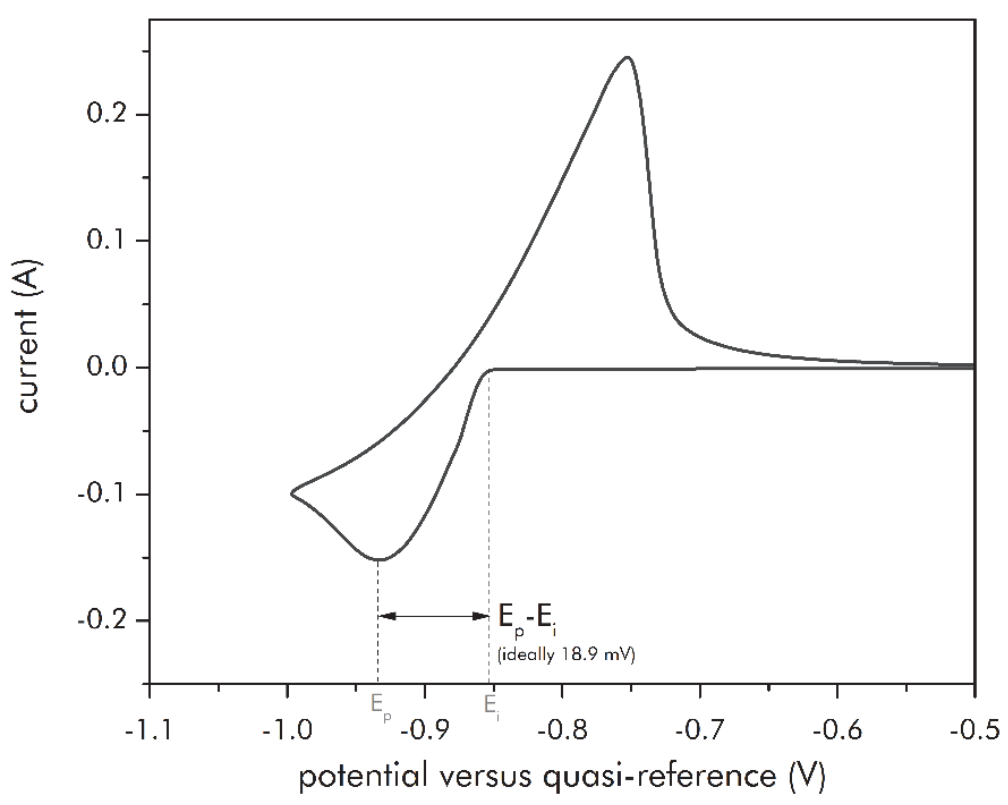

Figure 5. Typical CV for LiCl-KCl- $6.5 \mathrm{wt} \% \mathrm{UCl}_{3}$ salt (at $50 \mathrm{mV} / \mathrm{s}$ scan rate). Dilation of the reduction peak caused by $i R$ is clearly present as $E_{p}-E_{i}=80 \mathrm{mV}$, instead of the ideal value of $18.9 \mathrm{mV}$ (valid for $n=3, T=773 \mathrm{~K}$ )

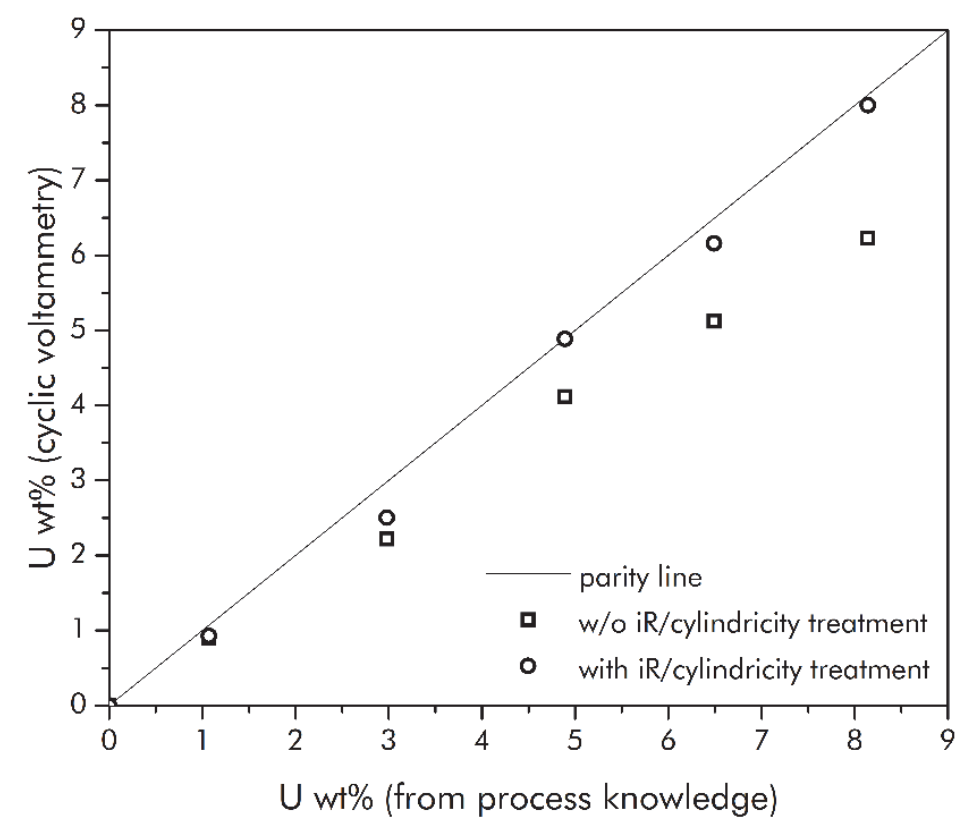

Figure 6. Parity plot comparing predicted uranium concentrations (with and without $i R /$ cylindricity treatment) versus known concentrations (from process knowledge) 


\subsection{Method Application to Fuel Processing Scenarios}

With the analytical approach suitably developed by the single-component salt tests, experiments of the fuel processing scenarios could be conducted. Table 1 shows the content of each of the salts that was used. Unfortunately, due to unavailability of a suitable neptunium salt, the third salt scenario (U, Pu, and $\mathrm{Np}$ at the prototypical steady-state) could not be run at this time but will be revisited as neptunium becomes available.

Table 1. Composition of salts (from process knowledge) for fuel processing scenarios

\begin{tabular}{lcccc} 
Salt No. & $\mathbf{U} \mathbf{w t} \%$ & $\mathbf{P u} \mathbf{w t} \%$ & $\mathbf{N p ~ w t \%}$ & Gd wt\% \\
\hline 001 (high U, low $\mathrm{Pu})$ & 1.49 & 0.5 & 0.0 & 0.0 \\
002 (low U, high $\mathrm{Pu})$ & 1.5 & 2.84 & 0.0 & 0.0 \\
003 (prototypical steady-state) & N/A & N/A & N/A & N/A \\
004 (high U, low Pu, high Gd) & 1.44 & 0.49 & 0.0 & 1.54
\end{tabular}

Typical reduction sweeps for the Salt 001 and Salt 002 cases are shown in Figures 7 and 8, respectively. Dilation of the uranium peak shows clear signs of $i R$ effects in both cases, thereby necessitating the improved analytical approach to achieve accurate concentration predictions. Furthermore, in both cases the plutonium current (found by subtracting the extrapolated uranium current from the total current) shows clear signs of UPCD behavior as there is a slow current rise that exists for roughly $\sim 150 \mathrm{mV}$ before the onset of overpotential deposition.

Fits of digital simulations to the plutonium peak are shown in both figures (using the CALPHAD activity data from Kurata [6]), and the shape of the $i-v$ curve is matched very well in both cases. The data taken for the SALT 004 scenario was found to be very similar to the SALT 001 results as the Gd peak is well negative of the $\mathrm{U}$ and $\mathrm{Pu}$ peaks and the amount of $\mathrm{Gd}$ added did not appear to alter diffusion coefficients or other behavior of the $\mathrm{U}^{3+}$ and $\mathrm{Pu}^{3+}$ ions.

The final predictions of the actinide concentrations in the tested salts are shown in Table 2. The predictions of the uranium content of the salts is quite good, and the prediction of the plutonium is reasonably good. It is not entirely clear why the plutonium concentrations are not matched as well as the uranium ones, but the issue is likely related to the extrapolation of the uranium current and the uncertainty of the activity data. Modeling adjustments and additional experimental tests will be investigated to determine if the results can be improved. 


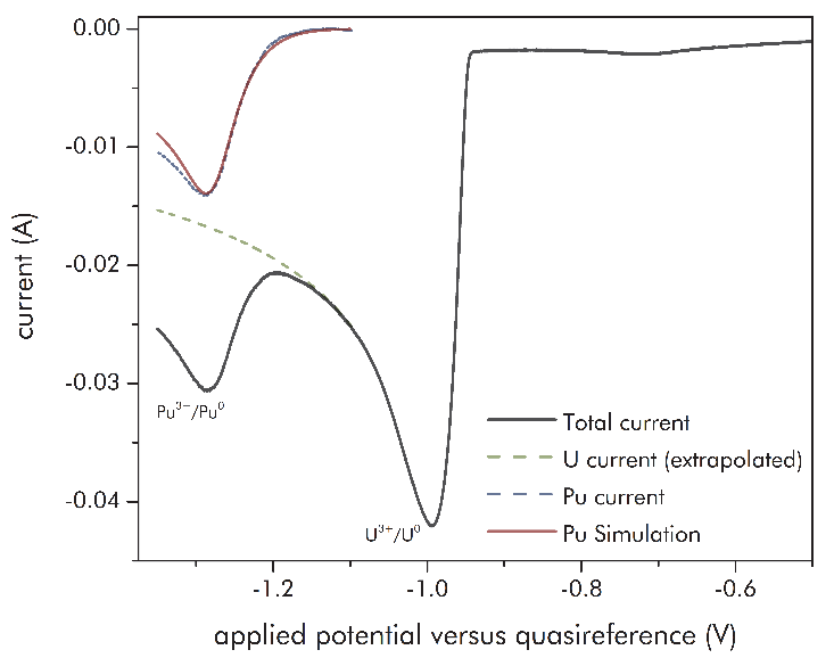

Figure 7. Typical CV reduction sweep for SALT 001 and simulation fit to plutonium peak

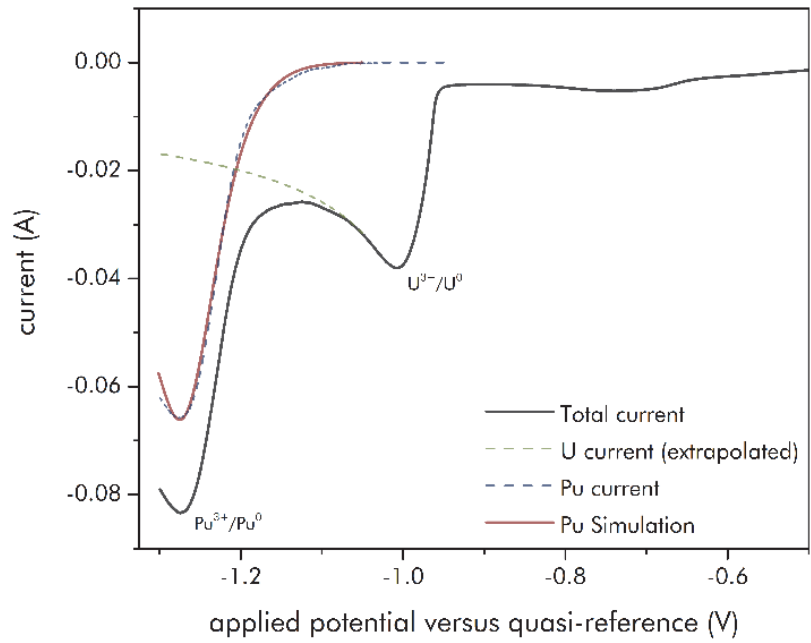

Figure 8. Typical CV reduction sweep for SALT 002 and simulation fit to plutonium peak

Table 2. Comparison of known actinide concentrations (from process knowledge) to electroanalytical predictions

\begin{tabular}{lcccr} 
Salt No. & $\begin{array}{c}\text { U wt\% } \\
\text { (process knowledge) }\end{array}$ & $\begin{array}{c}\text { U wt\% } \\
\text { (predicted) }\end{array}$ & $\begin{array}{c}\text { Pu wt\% } \\
\text { (process knowledge) }\end{array}$ & $\begin{array}{c}\text { Pu wt\% } \\
\text { (predict }\end{array}$ \\
\hline 001 (high U, low $\mathrm{Pu})$ & 1.49 & 1.46 & 0.5 & 0.45 \\
002 (low U, high $\mathrm{Pu})$ & 1.5 & 1.49 & 2.84 & 2.33 \\
003 (prototypical steady-state) & N/A & N/A & N/A & N/A \\
004 (high U, low $\mathrm{Pu}$, high Gd) & 1.44 & 1.42 & 0.49 & 0.52
\end{tabular}




\section{Conclusions}

The high concentrations and multi-species compositions of molten salts used in fuel processing create complications for electroanalytical methods. However, provided suitable modeling improvements are adopted, accurate measurements have been shown to still be possible. For single-component salts the improved analytical approach that has been developed has been shown to account for the attenuation of peak currents that occurs as concentrations are increased. For multicomponent salts the improved analytical approach has been shown to account for alterations to the current response that arise due to alloying effects in co-deposited metals.

The inclusion of neptunium in the prototypical steady-state scenario will add complexity to the analytical procedure that has been developed, but, ultimately, it is expected that the digital simulations will be able to account for its presence. Once neptunium does become available in FY17, tests will be performed to ensure the continued applicability of the modeling approach.

At present, the fitting of digital simulations to experimental CVs is a manually performed task that is somewhat time-consuming, but automation of the procedure could be readily developed. Doing so would ensure fast, timely processing of the voltammetric data, thereby permitting the methodology to be used for monitoring of real-world fuel processing equipment.

\section{References}

[1] M. Tylka, J. Willit, J. Prakash and M. Williamson, J. Electrochem. Soc., vol. 162, no. 9, pp. H625H633, 2015.

[2] M. Tylka, J. Willit, J. Prakash and M. Williamson, J. Electrochem Soc., vol. 162, no. 12, pp. H852H859, 2015.

[3] N. White and F. Lawson, Electroanalytical Chem. and Interfacial Electrochem., vol. 25, pp. 409-419, 1970.

[4] D. Garreau and J. Saveant, J. Electroanal. Chem., vol. 86, pp. 63-73, 1978.

[5] T. Berzins and P. Delahay, J. Am. Chem. Soc., pp. 555-559, 1953.

[6] M. Kurata, Calphad, vol. 23, no. 3-4, pp. 305-337, 1999.

[7] L. Leibowitz, R. Blomquist and A. Pelton, J. Nucl. Mater., vol. 184, pp. 59-64, 1991.

[8] M. Kurata and Y. Okamoto, presented at 1997 fall meeting of Japan Atomic Energy Society, 1997.

[9] J. Mallett, W. Shao, D. Liang and G. Zangari, Electro. and Solid-State Letters, vol. 12, no. 8, pp. D57D60, 2009. 